\title{
Chorioallantoic Membrane Tumor Model for Evaluating Oncolytic Viruses
}

\author{
Lea Krutzke, ${ }^{*}$ Ellen Allmendinger, Katja Hirt, and Stefan Kochanek \\ Department of Gene Therapy, Ulm University, Ulm, Germany.
}

Oncolytic viruses are promising anticancer agents; however, regarding their clinical efficacy, there is still significant scope for improvement. Preclinical in vivo evaluation of oncolytic viruses is mainly based on syngeneic or xenograft tumor models in mice, which is labor-intensive and time-consuming. Currently, a large proportion of developmental work in the research field of oncolytic viruses is directed toward overcoming cellular and noncellular barriers to achieve improved virus delivery to primary tumors and metastases. To evaluate the large number of genetically or chemically modified viruses regarding tumor delivery and biodistribution patterns, it would be valuable to have an in vivo model available that would allow easy screening experiments, that is of higher complexity than monoclonal cell lines, and that could be used as a platform method before confirmatory studies in small and large animals. Based on our data, we believe that the chicken chorioallantoic membrane (CAM) assay is a quick and low-cost high-throughput tumor model system for the in vivo analysis of oncolytic viruses. Here we describe the establishment, careful characterization, and optimization of the CAM model as an in vivo model for the evaluation of oncolytic viruses. We have used human adenovirus type 5 (HAdV-5) as an example for validation but are confident that the model can be used as a test system for replicating viruses of many different virus families. We show that the CAM tumor model enables intratumoral and intravenous virus administration and is a feasible and conclusive model for the analysis of relevant virus-host interactions, biodistribution patterns, and tumor-targeting profiles.

Keywords: chorioallantoic membrane, oncolytic virus, biodistribution, tumor targeting, adenovirus

\section{INTRODUCTION}

VIRUSES HAVE BEEN evaluated for treating patients with cancer diseases already since the second half of the 20th century. ${ }^{1}$ Currently, a variety of DNA and RNA viruses from many different virus families are investigated for their potential to serve as oncolytic viruses in solid cancers and cancer of the hematopoietic system. Examples are viruses based on vaccinia, measles, herpes simplex, and adenovirus. ${ }^{2}$ Before clinical testing can be considered, a thorough preclinical characterization of the candidate viruses, which often are genetically or chemically modified to enhance their antitumor properties, is essential.

While in vitro analysis of newly designed oncolytic viruses can rather easily be performed, investigation of both the complex virus-host interaction and the therapeutic potential of selected viruses mainly depends on the use of animals as specific tumor models. For example, the analysis of biodistribution, pharmacokinetics, tumor tar- geting, and efficacy largely depends on the use of xenograft tumor models in immunodeficient mice. If possible, syngeneic tumor models are also used, however, for human viruses this is often not the case, since animal models are not permissive for respective virus replication.

Studies in animals are under strict regulation and control by local and state competent authorities. Even if animal experiments are ethically justified and have been approved, suffering of animals with tumor growth can sometimes only be reduced but not completely avoided. In addition, costs for animal acquisition and care are high and in vivo experimentation in animals is labor-intensive and time-consuming. Therefore, both for ethical and practical reasons, there is good reason, as part of the $3 \mathrm{R}$ principles, to reduce and replace animal studies, whenever this is scientifically possible and justified.

The chorioallantoic membrane (CAM) model, based on fertilized chicken eggs, is a well-established tumor

${ }^{*}$ Correspondence: Dr. Lea Krutzke, Department of Gene Therapy, Ulm University, Helmholtzstr.8/1,89081 Ulm, Germany. E-mail: lea.krutzke@uni-ulm.de

(c) Lea Krutzke et al., 2020; Published by Mary Ann Liebert, Inc. This Open Access article is distributed under the terms of the Creative Commons Attribution Noncommercial License (http://creativecommons.org/licenses/by-nc/4.0/) which permits any noncommercial use, distribution, and reproduction in any medium, provided the original author(s) and the source are cited. 
model that has been studied already since the early 20th century, ${ }^{3,4}$ and we hypothesized it to be a valuable platform method to analyze oncolytic viruses before confirmatory studies in small and large animals. However, only a few studies have been published so far using the CAM model for the investigation of, for example, herpes simplex virus, adenovirus, or measles virus. ${ }^{5-11}$ The CAM model is characterized by a very fast tumor growth (several days instead of weeks) and it supports many cancer cell characteristics such as invasion, angiogenesis, and remodeling of the microenvironment. ${ }^{12}$ In addition, eggs are of low cost in acquisition and maintenance, the chick genome has a high-sequence conservation, the model is naturally immune-compromised thus allowing xenograft tumor transplantation, and ethical approval of experiments is not required. Moreover, established tumors and vessels are easily accessible, thus allowing for both intratumoral (i.t.) and intravenous (i.v.) substrate administration. ${ }^{12}$ We hypothesized that the CAM model might be a suitable model system to study biodistribution profiles and tumor targeting of oncolytic viruses. We assumed that the availability of such a quick and easy in vivo-like model system for the preclinical analysis of newly generated viruses could result in a preselection of oncolytic virus candidates that could be placed between in vitro studies in cell culture and in vivo studies in animals, thereby contributing to a reduction of regular animal studies. To evaluate the CAM model for the testing of oncolytic viruses, we used human adenovirus type 5 (HAdV-5) for proof-of-concept experiments to learn, to what degree virus-host interactions reported from humans and from murine models can be mirrored with the in ovo model.

Among the more than 80 known different human adenovirus types, HAdV-5 is most frequently used due to a comprehensive understanding of its life cycle, genome organization, and structure. Although many clinical studies have either been completed or are ongoing, ${ }^{13}$ the efficacy of HAdV-5-based oncolytic viruses has been limited so far, probably at least, in part, due to barriers imposed by complex nontarget vector-host interactions. Particularly, approaches that rely on systemic vector administration are significantly hampered by interactions with cellular and noncellular blood components that lead to substantial sequestration of particles. Well-known significant nontarget interactions are (1) the binding of HAdV-5 to human erythrocytes, ${ }^{14,15}$ (2) neutralization of particles by antibodies and complement proteins, ${ }^{16-18}$ (3) uptake of particles by macrophages, ${ }^{17,19,20}$ and (4) a strong hepatic tropism of HAdV-5. ${ }^{21}$

To investigate if and to what degree these sequestration mechanisms for HAdV-5 can be analyzed with the in ovo CAM model, we compared different vector administration routes, investigated various interactions of vector particles with chick blood components, thoroughly analyzed the in ovo biodistribution, its permissivity for HAdV-5, and the feasibility of this model to measure virus-induced oncolysis. When we performed our first experiments, we found ourselves confronted with various implementation problems, including very variable tumor growth, high mortality rate, extensive bleeding of the chick upon i.v. injections, and the lack of a proper method to sacrifice the chick. Therefore, in addition to describing in detail the method of using the CAM model for virus testing, we point out several critical technical aspects that have to be considered for successful use of the CAM tumor model for the investigation of oncolytic viruses.

Here we show that adenovirus-host interactions observed in humans and mice can be mirrored in the in ovo CAM model. We demonstrate that the CAM model represents a suitable model for the preclinical analysis not only of oncolytic adenoviruses but also of oncolytic viruses in general.

\section{MATERIAL AND METHODS Cell lines and cell culture}

A549 (ATCC CCL-185, split rate 1:8), A431 (ATCC CRL1555, split rate 1:8), SK-Mel-28 (ATCC HTB-72, split rate 1:3), and UM-SCC-11B (obtained from Prof. C. Brunner, University clinic Ulm, split rate 1:8) were passaged twice a week. Except for A549, which were cultivated in Minimum Essential Medium (MEM) (31095-029; Gibco), cell lines were cultivated in Dulbecco's Modified Eagle Medium (DMEM) (10938-025; Gibco) on tissue culture plates (83.3903; Sarstedt). Cells were incubated at $90 \%$ humidity, $5 \% \mathrm{CO}_{2}$, and $37^{\circ} \mathrm{C}$ in cell culture medium supplemented with $10 \%$ fetal calf serum (10270-106; Gibco) and $1 \%$ penicillin/streptomycin/glutamine (10378-016; Gibco).

\section{Chicken eggs}

White Lohmann LSL laying hen eggs were purchased from a German poultry farming company (LSL Rhein Main, Dieburg, Germany). Eggs were stored at $13^{\circ} \mathrm{C}$ upon arrival for no longer than 2 days. In accordance with the German Laboratory Animal Welfare Regulations ("Tierschutzversuchstierverordnung Abschnitt 2 §14"), experiments done with fertilized chicken eggs that are terminated before slip of the chick are not designated as animal experiments. Therefore, an approval by an Animal Care Commission is not required.

\section{Adenovirus vector}

A replication-incompetent HAdV-5 vector (GenBank ID: AY339865.1, sequence from nt 1 to 440 and from nt 3523 to 35935) had a deletion of the $E 1$ region and carried a CMV promoter-driven enhanced green fluorescent protein (eGFP) expression cassette, subcloned from a pEGFPN1 plasmid (6085-1; Clontech) that had been inserted in reverse orientation in place of the deleted E1 region. HAdV-5- $\triangle$ CAR vector particles carried additionally a point mutation in the fiber knob ( $\mathrm{Y} \rightarrow 477 \mathrm{~A})$ that significantly reduces CAR binding. ${ }^{22}$ HAdV-5- $\Delta F X$ vector particles additionally carried a point mutation in the 
hypervariable region 7 of the hexon protein (E $\rightarrow$ 451Q) that significantly reduces FX binding. ${ }^{23}$ Replicationcompetent wild-type adenovirus particles (HAdV-5wt) had no deletions but carried an eGFP expression cassette in forward orientation in a noncoding region between E1A and E1B (position 1648/1649).

\section{Adenovirus purification}

2E8-4E8 cells were infected with a pMOI of 400 and harvested $48 \mathrm{~h}$ later. For production, we used Elcomplementing N52.E6 cells ${ }^{24}$ for replication-incompetent vectors and A549 cells for replication-competent viruses. Cells were resuspended in $3 \mathrm{~mL}$ buffer $(50 \mathrm{mM}$ 4-[2hydroxyethyl]-1-piperazineethanesulfonic acid [HEPES], $150 \mathrm{mM} \mathrm{NaCl}, \mathrm{pH}$ 7.4), lysed by three freeze/thaw cycles, and purified by one $\mathrm{CsCl}$ step gradient (density bottom: $1.41 \mathrm{~g} / \mathrm{mL}$; density top: $1.27 \mathrm{~g} / \mathrm{mL} ; 2 \mathrm{~h}$ at $176,000 \mathrm{~g}, 4^{\circ} \mathrm{C}$ ) and one consecutive continuous $\mathrm{CsCl}$ gradient (density: $1.34 \mathrm{~g} /$ $\mathrm{mL} ; 20 \mathrm{~h}$ at $176,000 \mathrm{~g}$, and $4^{\circ} \mathrm{C}$ ). Subsequently, vector particles were desalted using PD-10 size exclusion columns (17-0851-01; GE Healthcare) and stored in buffer (50 mM HEPES, $150 \mathrm{mM} \mathrm{NaCl}, \mathrm{pH} 7.4$ ) with $10 \%$ glycerol at $-80^{\circ} \mathrm{C}$. Physical vector titers were determined by optical density measurement at $\mathrm{OD}_{260 \mathrm{~nm}}$ of isolated virus/vector DNA. ${ }^{25}$

\section{Transduction assays}

2E4 cells were seeded in $200 \mu \mathrm{L}$ on coated, flatbottomed 96-well plates (167008; Thermo Fisher). The next day, cells were washed with $100 \mu \mathrm{L}$ phosphatebuffered saline (PBS), $100 \mu \mathrm{L}$ serum-free medium was added, and cells were transduced with $2 \mathrm{E} 7$ vector particles (pMOI 1,000) in triplicate and incubated for $4 \mathrm{~h}$ at $37^{\circ} \mathrm{C}$. Subsequently, the medium was aspirated, cells were washed with $100 \mu \mathrm{L}$ PBS, $200 \mu \mathrm{L}$ serum-containing medium was added, and cells were incubated at $37^{\circ} \mathrm{C}$. If plasma was used for preincubation, $2 \mathrm{E} 7$ vector particles in a total volume of $2 \mu \mathrm{L}$ were incubated with $10 \mu \mathrm{L}$ plasma for $10 \mathrm{~min}$ at $37^{\circ} \mathrm{C}$ before they were given to the cells. Twenty-four hours post-transduction, cells were harvested and eGFP expression was analyzed by flow cytometry.

For plasma preparations, blood was collected from voluntary humans, BALB/c mice, nude mice, NOD scid gamma (NSG) mice, or chicks at embryonic day 14 by vessel puncture and anticoagulated with $100 \mathrm{mg} / \mathrm{mL}$ hirudin (Refludan, Celgene Europe LTd., CAS 138068-37-8, discontinued) to preserve complement activity. Subsequently, samples were centrifuged for $10 \mathrm{~min}$ at $800 \mathrm{~g}$, and plasma fractions were separated and stored at $-20^{\circ} \mathrm{C}$.

\section{Vector binding to blood cells}

All blood samples were anticoagulated with $100 \mathrm{mg} / \mathrm{mL}$ hirudin to preserve complement activity. Mice and chicks, as well as enzyme-linked immunosorbent assay (ELISA)tested human blood donors, were HAdV-5-naive. Fifty microliters of whole-blood samples was incubated with
HAdV-5 vector particles dissolved in $25 \mu \mathrm{L}$ PBS. To avoid saturation of erythrocytes, a vector to erythrocyte ratio of $1: 10$ was chosen, ${ }^{26}$ and thus, vector doses that were incubated with blood samples were adapted depending on the species. Based on red blood cell counts, humans have $\sim 5 \mathrm{E} 6$ erythrocytes $/ \mu \mathrm{L}$, mice have $\sim 1 \mathrm{E} 7$ erythrocytes $/ \mu \mathrm{L}$, and chicks have $\sim 1 \mathrm{E} 6$ erythrocytes $/ \mu \mathrm{L}$. Thus, $50 \mu \mathrm{L}$ of human whole blood was incubated with $2.5 \mathrm{E} 7 \mathrm{VP}, 50 \mu \mathrm{L}$ of murine whole blood was incubated with $5 \mathrm{E} 7 \mathrm{VP}$, and $50 \mu \mathrm{L}$ of chick whole blood was incubated with 5E6 VP. Samples were incubated for $30 \mathrm{~min}$ at $37^{\circ} \mathrm{C}$ rotating. Subsequently, samples were centrifuged for $10 \mathrm{~min}$ at $800 \mathrm{~g}$ to separate plasma and cell fractions. The cell fraction was washed once with $1 \mathrm{~mL}$ PBS, before both plasma and cell fractions were adjusted to a volume of $75 \mu \mathrm{L}$ with PBS. Twenty microliters of both fractions was used for DNA isolations. DNA was isolated using the GenElute Mammalian Genomic DNA Miniprep Kit (G1N350; Sigma) according to the manual. To avoid saturation of the columns, the cell fraction of chick blood was diluted 1:25 beforehand, since avian erythrocytes are nucleated. Subsequently, the adenovirus content of each fraction was analyzed by quantitative PCR (qPCR) analysis.

\section{qPCR analysis}

Adenoviral E4 copy number of DNA samples was determined by qPCR, and values normalized to $\beta$-actin copy numbers. Two-microliter samples were mixed with $10 \mu \mathrm{L}$ SYBR Green (KK4502; Kapa Biosystems), and $0.4 \mu \mathrm{L} 10 \mathrm{pmol} / \mu \mathrm{L}$ primer of each forward and reverse (for E4: forward 5'-tagacgatccetactgtacg-3'; reverse 5'ggaaatatgactacgtccgg- $3^{\prime}$; for human $\beta$-actin: forward $5^{\prime}$ gctcctcctgagcgcaag- $3^{\prime}$; reverse $5^{\prime}$-catctgctggaaggtggaca- $3^{\prime}$; for murine $\beta$-actin: forward $5^{\prime}$ - caaggagtgcaagaacacag- $3^{\prime}$; reverse $5^{\prime}$-gccttggagtgtgtattgag- $3^{\prime}$; for chick $\beta$-actin: forward $5^{\prime}$-gctcctcetgagcgcaag- $3^{\prime}$; reverse $5^{\prime}$-catctgctggaa ggtggaca- $3^{\prime}$ ) in a final volume of $20 \mu \mathrm{L}$. Thermocycles were performed as follows: 1 cycle: $10 \mathrm{~min} 95^{\circ} \mathrm{C} ; 40$ cycles: 30 s $95^{\circ} \mathrm{C}-30$ s $60^{\circ} \mathrm{C}-8 \mathrm{~s} 72^{\circ} \mathrm{C}$; 1 cycle: $10 \min 72^{\circ} \mathrm{C}$.

\section{CAM assay}

At embryonic day (E) 0, eggs were carefully wiped with lukewarm tap water and incubated in a horizontal position (pointed side opposite to blunt side) at $37.8^{\circ} \mathrm{C}$ and $58-60 \%$ relative humidity (ProCon Grumbach, Compact S84 with automatic turning trays). Five times a day, eggs were automatically turned by $180^{\circ}$ at only $6 \%$ s to prevent vibration of eggs. At E4, a small hole was drilled in the pointed end of the egg (DREMEL 3000, $230 \mathrm{~V}-50 \mathrm{~Hz} 130 \mathrm{~W}$ n:33,000/ min) to penetrate the peel skin and eggs were incubated for $10 \mathrm{~min}$ in an upright position at $37.8^{\circ} \mathrm{C}$ for air escape and deepening of egg content. Subsequently, the hole was sealed with a patch (46834-00; Leukosilk S), enlarged with a scissors to an opening of $1 \mathrm{~cm}$ in diameter, and again sealed with a second patch. Henceforth, eggs were 
incubated in the upright position without turning. At E7, a 1-mm-thick silicone ring with an inner diameter of $5 \mathrm{~mm}$ was placed on the CAM atop a branching vessel. At E8, cells were detached from cell culture plates by incubation with Accutase (A6964; Sigma), centrifuged for $10 \mathrm{~min}$ at $300 \mathrm{~g}$, washed once with PBS, and resuspended in serumfree medium. 3E6 cells in a final volume of $15 \mu \mathrm{L}$ were mixed with $10 \mu \mathrm{L}$ ice-cold Matrigel (356237; Corning) and applied to the silicone ring on the CAM. The openings were sealed with a patch and eggs were further incubated. At E12 (E11 for replication-competent HAdV-5wt), the openings of the eggs were enlarged to allow i.v. or i.t. injection of 5E9 vector or virus particles dissolved in $50 \mu \mathrm{L}$ PBS with a Gx1/2 $0.4 \times 12 \mathrm{~mm}$ cannula (4657705; Braun Sterican). Due to the poor coagulation of the chick blood at this developmental stage, the cannula was not removed from the vessel after i.v. injection, but the syringe was removed, and the cannula closed with a silicone plug and fixed to the eggshell using several patches. After injection, the eggs were incubated for further $48 \mathrm{~h}(120 \mathrm{~h}$ for replication-competent HAdV-5wt). At E14 (E16 for replication-competent HAdV-5wt), chicks were sacrificed by i.v. injection of overdosed Propofol $(3 \mathrm{mg} / \mathrm{egg}$; 2061108; Braun). Tumors and organs were collected, frozen in liquid nitrogen, and stored at $-80^{\circ} \mathrm{C}$ or directly used for reinfection assays. To analyze tumor shrinkage, tumors were weighed before freezing. To quantify the in ovo biodistribution of vector particles, tissue samples were either (1) homogenized and the eGFP expression was analyzed by fluorometry or (2) total DNA of small tissue pieces was isolated using the GenElute Mammalian Genomic DNA Miniprep Kit (G1N350; Sigma) according to the manual, and the adenoviral DNA content was analyzed by qPCR. To analyze tumor growth of different cell lines, tumors were collected at E12, microscopic pictures were taken (fivefold magnification), length and width were measured using Image $1.51 \mathrm{~s}^{27,28}$ based on the knowledge of the silicone ring diameter, and tumor volumes were calculated as length $\times$ width $^{2} \times 1 / 2{ }^{29}$ To visualize transduction or infection of tumor cells, $6 \mu \mathrm{m}$ tumor tissue cryosections were covered with a fluorescence mounting medium (53023; Dako) and analyzed for eGFP-expressing cells by fluorescence microscopy.

\section{Fluorometric analysis of organ and tumor homogenates}

Organ and tumor pieces with a size of $\sim 2 \times 2 \mathrm{~mm}$ were homogenized with a $0.2 \mathrm{~mL}$ tissue grinder (357848; Wheaton) in $200 \mu \mathrm{L}$ Tris buffered saline (TBS) $\mathrm{pH} 7.4$ containing $1 \times$ protease inhibitor (11873580001; Thermo Fisher), and were incubated for $10 \mathrm{~min}$ at room temperature before they were put on ice. Samples were centrifuged twice at 20,817 $g$ and the plain supernatants were transferred to new tubes. Protein concentration of samples was determined by optical density measurements at $280 \mathrm{~nm}$. The eGFP fluorescence intensity of $2 \mu \mathrm{L}$ sample was analyzed using a fluorospectrometer (3300; NanoDrop, excitation: $488 \mathrm{~nm}$; emission: $512 \mathrm{~nm}$ ). Results are given as response fluorescence units (RFU)/mg protein.

\section{Analysis of permissivity}

Tissues from vector- or virus-injected chicks were isolated at E14 and homogenized in $5 \mathrm{~mL}$ PBS by passing the tissue through $100 \mu \mathrm{m}$ filters. Subsequently, cell homogenates were centrifuged for $10 \mathrm{~min}$ at 4,000 $\mathrm{g}$. Pellets were resuspended in PBS in a final volume of $300 \mu \mathrm{L}$, and cells were lysed by three freeze/thaw cycles. Cell debris was removed by centrifugation for $10 \mathrm{~min}$ at $4,000 \mathrm{~g}$. One-third of supernatants was incubated in triplicate with 2E4 A549 cells that were seeded the day before in $100 \mu \mathrm{L}$ medium. After $3 \mathrm{~h}$ of incubation at $37^{\circ} \mathrm{C}, \mathrm{A} 549$ cells were washed twice with $100 \mu \mathrm{L}$ PBS. Subsequently, cells were either (1) harvested, the DNA isolated using GenElute Mammalian Genomic DNA Miniprep Kit (G1N350; Sigma) according to the manual, and the adenoviral E4 copy number determined by qPCR, or (2) supplemented with $200 \mu \mathrm{L}$ serum-containing medium, incubated for $24 \mathrm{~h}$, and the eGFP expression was analyzed by fluorescence microscopy.

\section{Immunohistochemistry}

Six-micron tumor tissue cryosections were dried overnight. The next day, sections were fixed with ice-cold acetone for $12 \mathrm{~min}$ at $-20^{\circ} \mathrm{C}$ and blocked for $1 \mathrm{~h}$ at room temperature with 10\% goat serum (X0907; Dako). Subsequently, sections were covered with the $\alpha$-CD31 antibody (1:200 in antibody diluent Dako S2022; LsBio LSC348310) and incubated overnight at $4^{\circ} \mathrm{C}$. The next day, sections were washed three times for 5 min with PBS and covered with the goat $\alpha$-rabbit IgG-Alexa488 antibody (1:500; a11070; Invitrogen) for $1 \mathrm{~h}$ at room temperature. Subsequently, sections were washed three times for $5 \mathrm{~min}$ with PBS, incubated with DAPI (1:5,000; D9542; Sigma) for $3 \mathrm{~min}$, and again washed. Finally, sections were covered with the fluorescence mounting medium (S3023; Dako) and analyzed by fluorescence microscopy.

\section{Statistics}

Statistical analysis was performed using the unpaired two-sample (Welch) Student's $t$-test or Wilcox test with RStudio software version 3.6.1. ${ }^{30}$ Results are given as mean \pm standard deviation. $p$-Values $\leq 0.05$ were considered statistically significant.

\section{RESULTS}

\section{Reproducible tumor growth on CAM of fertilized chicken eggs}

To establish the CAM tumor model for biodistribution analysis of oncolytic adenoviruses, we tested and improved general and specific parameters of the CAM model. 
We set up a robust protocol (Fig. 1A and detailed description in the method part) and identified the following essential steps that significantly influence tumor take rate, vascularization and growth, and the generation of stable data sets: (1) Breeding of eggs at E0 has to be started early in the morning to obtain well-developed vessels at E7 for the positioning of the silicone ring. (2) Positioning of the silicone ring onto a branched, well-developed vessel is crucial to achieve good vascularization, nutrient supply, and growth of the tumor. (3) Application of tumor cells onto the CAM before E8 and (4) application of less than 3E6 cells onto the CAM results in poor tumor growth. (5) The i.v. injection of volumes of $50-100 \mu \mathrm{L}$ is feasible. (6) i.v. injection later than E16 is not feasible due to hindered penetration of the dehydrating CAM. (7) The i.v. administration of adenoviral vector doses higher than 5E9 VP/ egg results in increased mortality. (8) Chick blood possesses poor coagulation at this developmental stage. However, to avoid efflux of adenoviral particles and increased mortality after i.v. injection, it is mandatory to prevent extensive bleeding. Neither sealing with protective spray dressing nor obliteration by electrocautery or heat enabled proper wound closure. Therefore, we recommend removing the syringe, but retaining the cannula in the vessel and fixing it to the eggshell (Supplementary Video S1).

Even though experiments with fertilized eggs, according to the German Protection of Animals Act, are not designated as animal experiments as long as experiments are terminated before hatch of the chick, we suggest the use of a compassionate method to sacrifice the chick. Since little is known about the chick's awareness and its ability to sense pain during these early developmental stages, we recommend an overdosed i.v. injection of the anesthetic propofol.

We tested four different human cancer cell lines on their capability to form within 5 days reproducible tumors on the CAM of fertilized chicken eggs. Application of A549 cells resulted in the formation of no or only very small and hardly vascularized tumors. However, since

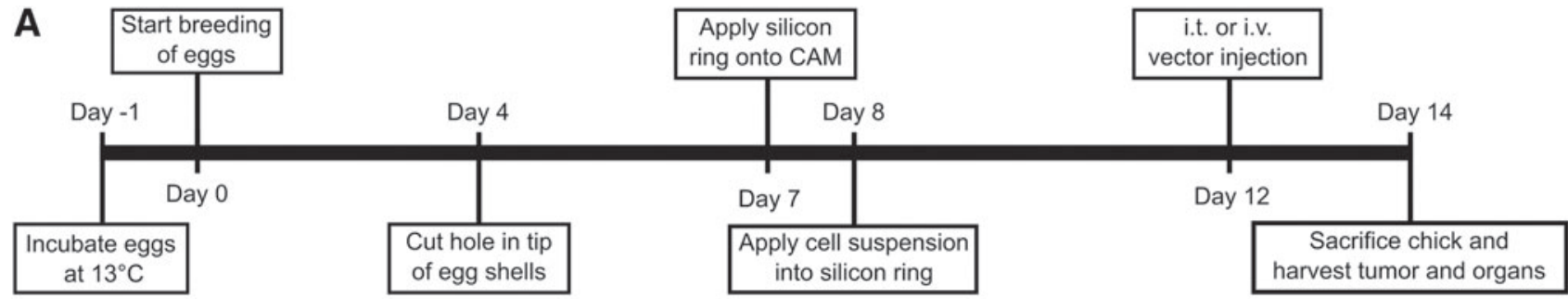

B

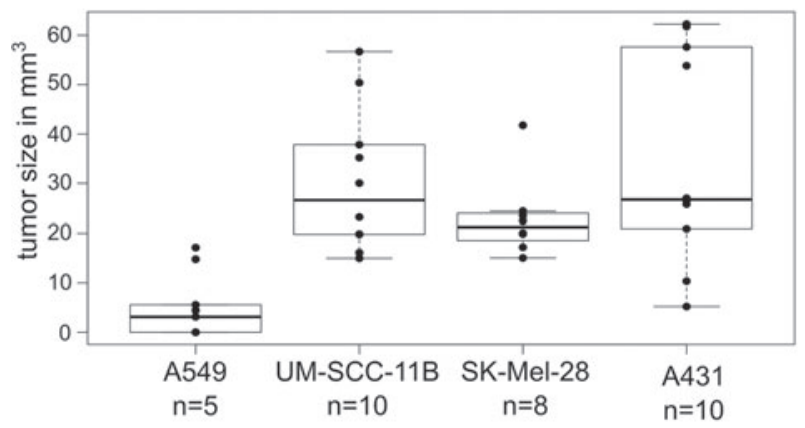

E
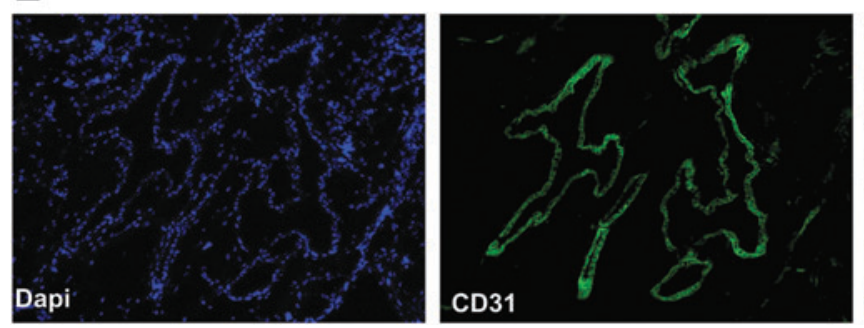

C

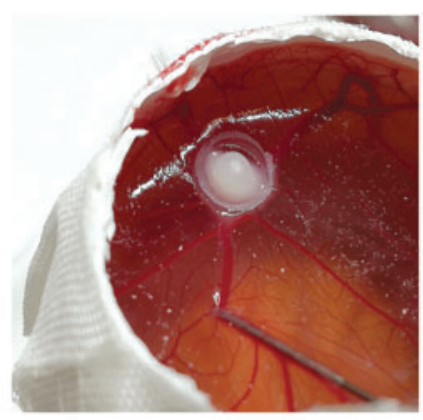

D

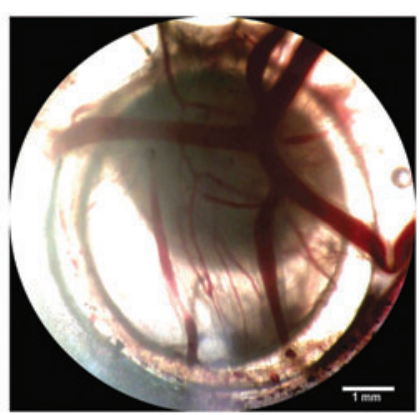

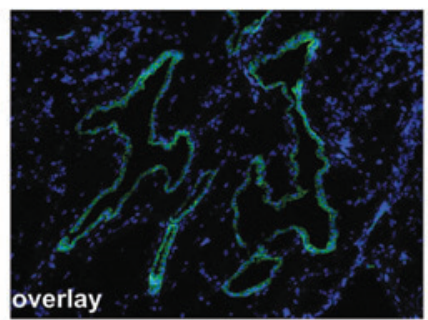

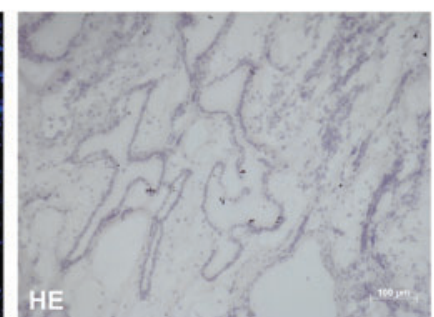

Figure 1. Characterization of human xenograft tumors on CAM of fertilized chicken eggs. (A) Timescale for reproducible human xenograft tumor growth on the CAM allowing for HAdV-5 administration and analysis. (B) $3 \mathrm{E} 6$ cells of various human cancer cell lines in $15 \mu \mathrm{L}$ serum-free medium were mixed with $10 \mu \mathrm{L}$ Matrigel and applied onto the CAM at E8. Tumor sizes were measured at E12 by microscopy analysis. (C) Macroscopic picture of human UM-SCC-11B tumor on a CAM at E12. (D) Bottom-up microscopic picture of dissected tumor with silicone ring on a CAM at E12. Scale bar: $1 \mathrm{~mm}$. (E) Endothelial cells were stained in tumor sections with an $\alpha$-CD31 antibody to analyze vascularization. Scale bar: $100 \mu \mathrm{m}$. CAM, chorioallantoic membrane; HAdV-5, human adenovirus type 5 . 
our laboratory is primarily interested in epidermal growth factor receptor (EGFR)-positive and EGFR-negative tumor entities, we next tested the head and neck squamous carcinoma cell line UM-SCC-11B (EGFR positive), the malignant melanoma cell line SK-Mel-28 (EGFR negative), and the epidermoid carcinoma cell line A431 (EGFR positive). All three cell lines formed reproducible tumors (Fig. 1B, C). Vascularization of tumors could be seen by the naked eye by means of vessels that infiltrated the tumors (Fig. 1D). Vascularization was additionally confirmed by immunohistochemical staining with an endothelial cell marker anti-CD31 antibody (Fig. 1E).

\section{Improved i.t. virus distribution upon i.v. injection}

Oncolytic adenoviruses are given either by i.t. or i.v. injection. i.t. administration ensures the delivery of the virus directly to the desired tissue and circumvents the problem of sufficient tumor targeting upon systemic administration. However, after i.t. injection, virus distribution within the tissue is poor and mainly limited to the injection side. Although tumor uptake of adenovirus particle after i.v. administration is inhibited by various nontarget interactions and sequestrations, a more even distribution of virus particles throughout the entire tumor tissue would be beneficial for therapeutic activity.

To analyze if the CAM tumor model is suitable to analyze the biodistribution of both i.t.- and i.v.-administered adenoviral particles, we injected 5E9 eGFP-expressing
HAdV-5 vector particles by both administration routes. Two days later, the tumors were harvested and the distribution of eGFP-expressing cells was compared in cryosections by fluorescence microscopy (Fig. 2 and Supplementary Fig. S1). In i.t. injected tumors, the eGFPpositive cells were locally restricted to the injection site, while in i.v. injected tumors, the transduced cells were broadly distributed throughout the entire tissue. This pattern exactly mirrors what has been observed in murine tumors, and confirms that the CAM tumor model is feasible for both i.t. and i.v. administration of adenoviral vector particles. ${ }^{31,32}$

\section{Avian plasma enhances HAdV-5-mediated cell transduction}

Several studies analyzed and showed the enhancing effect of serum or plasma from mice and humans on the cellular transduction with HAdV-5-based vectors. ${ }^{23,33,34}$ This effect can most likely be predominantly attributed to the binding of blood coagulation factor $\mathrm{X}(\mathrm{FX})$ to the adenoviral capsid protein hexon. ${ }^{35,36}$ To examine if this effect also takes place in the fertilized chicken egg, we compared in vitro cell transduction efficiencies of HAdV5 in the presence of human, murine, or chick plasma. Results clearly showed that plasma samples from all species significantly enhanced HAdV-5 cell transduction compared with vector particles incubated in PBS. While human plasma enhanced HAdV-5 cell transduction significantly stronger (6.7-fold; $p<2 \mathrm{E}-5)$, chick plasma

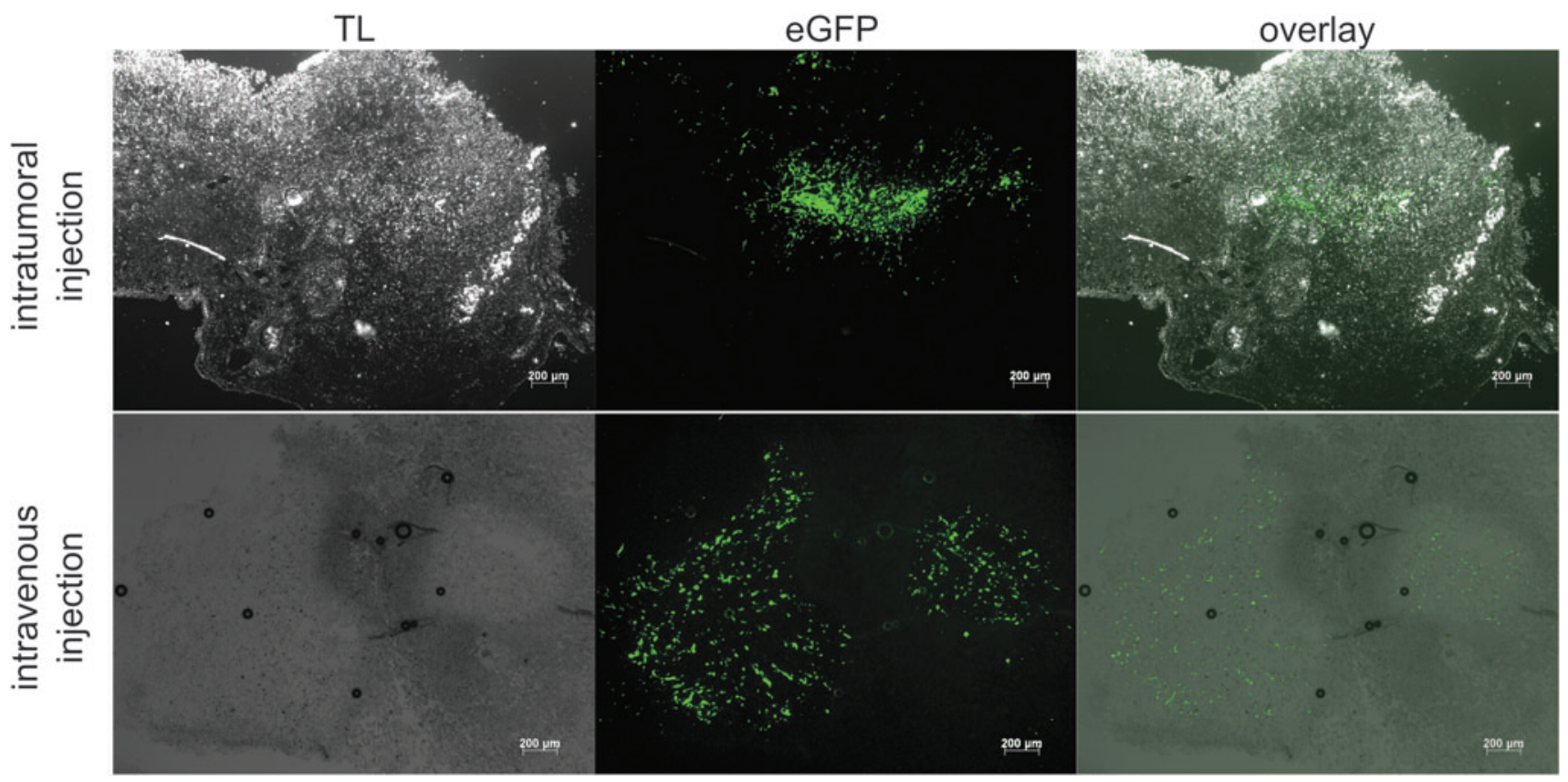

Figure 2. Improved intratumoral HAdV-5 spread following intravenous vector administration. 5E9 eGFP-expressing replication-incompetent HAdV-5 vector particles dissolved in $50 \mu \mathrm{L}$ PBS were either intratumorally or intravenously injected in human UM-SCC-11B tumor-bearing fertilized chicken eggs at E12. At E14 chicks were sacrificed, and tumors were harvested and frozen in liquid nitrogen. Six-micron cryosections of tumors were prepared and analyzed for eGFPexpressing cells by fluorescence microscopy. Scale bar $200 \mu \mathrm{m}$, fivefold magnification, representative data of $n=5$. eGFP, enhanced green fluorescent protein; PBS, phosphate-buffered saline; TL, transmitted light. 
(5.1-fold; $p<0.03$ ) had a similar enhancing effect on viral cell transduction as murine plasma (4.6-fold; $p<9 \mathrm{E}-7)$ (Fig. 3A).

\section{Avian plasma does not neutralize HAdV-5 vector particles in the absence of FX-binding}

In 2013, Xu et al. showed that binding of FX to the adenoviral hexon protein of HAdV-5 shields vector particles from neutralization by natural $\operatorname{IgM}$ antibodies and complements. ${ }^{18}$ To analyze if this also occurs in the chick plasma, we tested its effect on the cellular transduction with mutant HAdV-5- $\Delta \mathrm{FX}$ vectors. Vector particles carried a point mutation within the hypervariable region 7 of the hexon protein that significantly reduces binding of FX to the capsid. ${ }^{23}$ Results demonstrated significant neutralization of mutant HAdV-5- $\Delta \mathrm{FX}$ vector particles in plasma of BALB/c mice (B and T cells) $(p<1.4 \mathrm{E}-4$ compared with PBS) and nude mice (lacking $\mathrm{T}$ but not $\mathrm{B}$ cells ${ }^{37}$ )
( $p<5 \mathrm{E}-4$ compared with PBS). In contrast, plasma of NSG mice (lacking T and B cells) and of chicks had no neutralizing effect on HAdV-5- $\Delta \mathrm{FX}$, but rather enhanced transduction (for NSG plasma: $p<1 \mathrm{E}-3$ compared with PBS; for chick plasma: $p<1 \mathrm{E}-3$ compared with PBS) (Fig. 3B).

\section{HAdV-5 does not bind to avian blood cells}

Another major nontarget interaction of HAdV-5 is the binding to human erythrocytes, which is mediated either by binding of the adenoviral fiber knob to CAR or by anti-adenovirus antibody-mediated binding to complement receptor $1 .^{14}$ This effect can also be observed in rats, however, not in mice. ${ }^{15}$ To analyze if HAdV-5 binds to avian erythrocytes, we incubated vector particles with hirudinized human, murine, or chick blood samples, subsequently separated plasma and cell fractions, and quantified the respective adenoviral DNA content by qPCR.
A

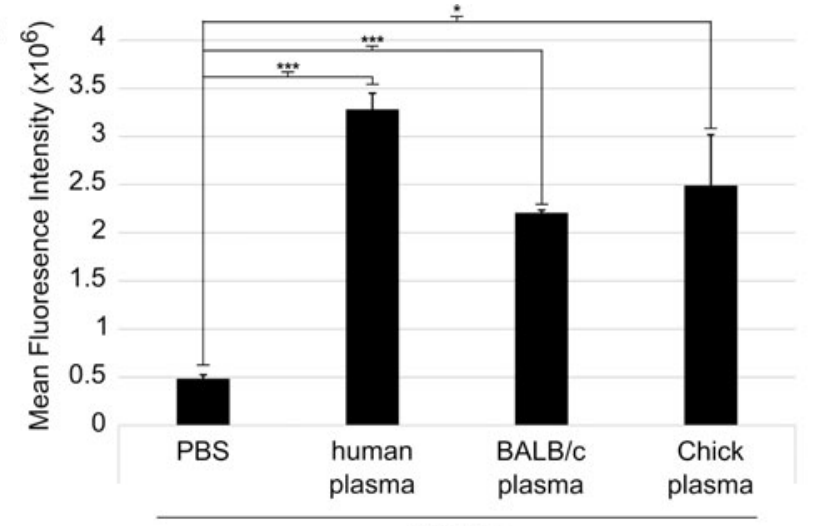

HAdV-5

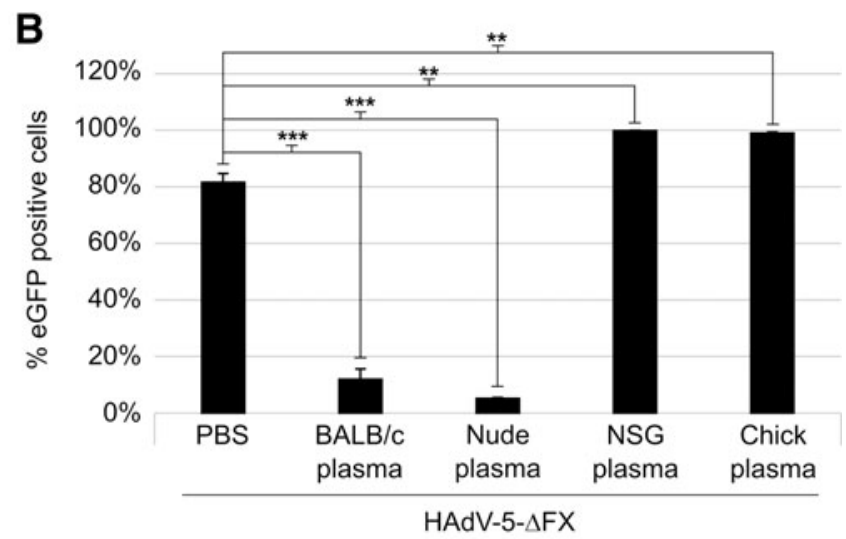

C
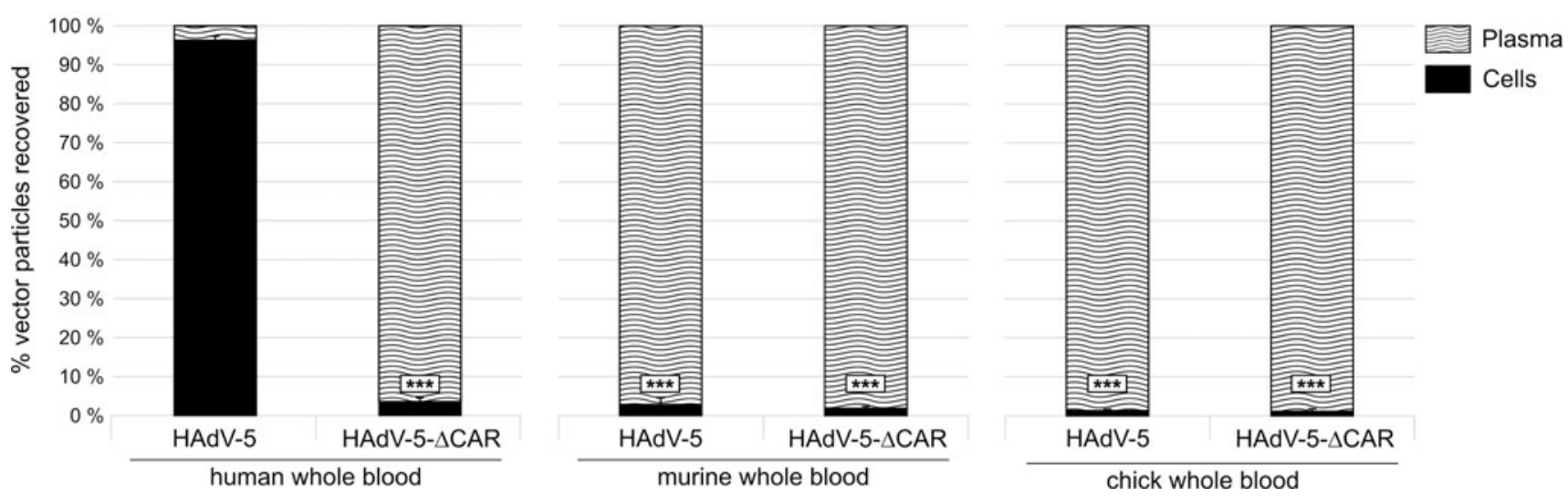

Figure 3. Similar effects of murine and chick blood components on HAdV-5. 2E7 (A), HAdV-5 or (B) HAdV-5- $\triangle F X$ eGFP-expressing replication-incompetent vector particles dissolved in $2 \mu \mathrm{L}$ PBS were incubated for $10 \mathrm{~min}$ at $37^{\circ} \mathrm{C}$ with $10 \mu \mathrm{L}$ PBS or hirudinized HAdV-5-naive human, BALB/c, nude mice, NSG mice, or chick plasma. Subsequently, 2E4 A549 cells, seeded the day before, were transduced and incubated at $37^{\circ} \mathrm{C}$. Twenty-four hours post-transduction, the eGFPexpression was analyzed by flow cytometry. Results are representative for three independent experiments. (C) HAdV-5 or HAdV-5- $\triangle \mathrm{CAR}$ vector particles in a final volume of $25 \mu \mathrm{L}$ were incubated with $50 \mu \mathrm{L}$ of hirudinized HAdV-5-naive human, murine, or avian whole-blood samples for 30 min at $37^{\circ} \mathrm{C}$ in a vector to erythrocyte ratio of 1:10 to avoid saturation of cells. Subsequently, cell and plasma fractions were separated by centrifugation, fractions were adjusted to the initial volume with PBS, and total DNA of $20 \mu \mathrm{L}$ of each fraction was extracted. Since avian erythrocytes are nucleated, cell fractions of chick blood were diluted 1:25 before DNA isolation to avoid saturation of the purification columns. The vector copy number was quantified by qPCR and normalized to $\beta$-actin copy numbers. Results are given as mean of $n=3 \pm$ standard deviation. ${ }^{*} p<0.05,{ }^{* *} p<0.005,{ }^{* * *} p<0.0005$. qPCR, quantitative PCR. 
To analyze a CAR-mediated binding, a CAR-binding deleted mutant vector HAdV-5- $\triangle$ CAR was included. HAdV-5- $\triangle$ CAR carried a point mutation in the fiber knob that significantly reduces CAR binding. ${ }^{22}$ To exclude antibody-mediated binding to blood cells, we used plasma of HAdV-5-naive animals and ELISA-confirmed HAdV-5-naive humans. As previously published, results confirmed that in the absence of adenovirus-specific antibodies, HAdV-5 binds to human erythrocytes in a CAR-dependent manner. ${ }^{14,23}$ In contrast, no cell binding was observed with murine or avian blood samples, with neither of both vectors $(p<3 \mathrm{E}-16$ for all samples compared with HAdV-5 in human whole blood) (Fig. 3C).

\section{Chick is not permissive for HAdV-5 replication}

Replication of human adenoviruses is restricted mainly to human cells. While Syrian hamsters, New Zealand rabbits, cows, and cotton rats have been shown to be semipermissive for HAdV-5, ${ }^{38-41}$ the virus cannot replicate in murine tissue. ${ }^{42}$ To analyze if chicks are permissive for HAdV-5, we systemically injected replication-competent eGFP-expressing wild-type adenovirus particles HAdV$5 \mathrm{wt}$ into human tumor-bearing fertilized eggs. Two days later, organs and human tumors were harvested, lysed to release potential newly produced viral particles, and used for in vitro reinfection of A549 cells. Microscopic analysis showed that the cell shape of naturally spindle-shaped A549 cells changed to a rounded appearance. We believe this was likely due to a slightly toxic effect of the tissue lysates (Fig. 4A). However, fluorescence microscopy revealed that GFP-positive and thus virus-infected A549 cells were only apparent in human tumor lysate-reinfected A549 cells. To verify these data, reinfected A549 cells were harvested, and the adenoviral DNA content was quantified by qPCR analysis. Results confirmed that adenoviral DNA was only detected in human tumor lysatereinfected A549 cells $(p<0.01$ for tumor lysate compared with all samples) (Fig. 4B). This indicated that replication of HAdV-5 occurred only in human tumor tissues but not in chick tissues.

\section{In ovo biodistribution of HAdV-5}

Next, we analyzed the in ovo biodistribution of systemically injected HAdV-5. 5E9 replication-incompetent HAdV-5 vector particles were intravenously injected in fertilized, tumor-bearing chicken eggs. Two day later, chicks were sacrificed, tissues and tumors were harvested, and either the transduction efficiency was analyzed by fluorometric analysis of eGFP expression (Fig. 5A) or the respective adenoviral DNA content was quantified by qPCR (Fig. 5B). Results showed that the strongest eGFP expression was detected in liver tissue, second strongest cell transduction was observed in the spleen, moderate expression was observed in the heart and kidney, and very weak expression was detected in the stomach and brain tissue (Fig. 5A). This biodistribution profile exactly mirrored published distribution patterns observed in mice upon i.v. injection of HAdV-5 vector particles. ${ }^{31,32} \mathrm{Im}$ portantly, a substantial amount of injected vector particles transduced the applied human tumor cells, which further confirms vascularization of grown tumors and the applicability of this model system to analyze oncolytic adenoviruses regarding biodistribution and tumor targeting profiles.

Interestingly, quantification of viral genome copy numbers in tumor and chick organs revealed a considerably different result than functional transduction analysis. Here, a substantial amount of viral DNA was detected in the kidney, while vector genome copy numbers in tumor and other chick organs were statistical significantly lower (Fig. 5B). Most likely, the discrepancy between eGFP expression profile and vector genome copy numbers in the kidney can be explained by the fact that poultry secretes toxins primarily through the kidney and the gallbladder routes. ${ }^{43}$

\section{Insufficient in ovo oncolysis by HAdV-5wt due to limited incubation period}

To investigate if the in ovo tumor model enables the analysis of virus replication-induced oncolysis, we injected eGFP-expressing, replication-competent HAdV-5wt virus or replication-incompetent $\mathrm{HAdV}-5$ vector particles in tumor-bearing eggs. Extension of egg breeding beyond E16 is not recommended due to animal protection reasons. At this developmental stage, the CAM is considerably desiccated and i.v. propofol injection to sacrifice the chick is not feasible anymore. Hence, to extend the time slot from virus injection to termination of the experiment, i.v. injections were done already at E11 instead at E12. Eggs were incubated for five more days, to allow at least one or two cycles of virus replication, before tumors were excised.

Fluorescence microscopy of tumor cryosections revealed increased numbers of eGFP-expressing cells of tumors grown on eggs injected with HAdV-5wt compared with tumors grown on eggs injected with HAdV-5 (Fig. 6A). This indicated i.t. replication of HAdV-5wt. QPCR-based quantification of viral genome copy numbers showed a statistically significant, 4,000-fold elevated viral DNA content $(p<2.8 \mathrm{E}-4)$ in tumors of eggs injected with HAdV-5wt, thus confirming i.t. replication (Fig. 6B). However, tumor shrinkage or growth delay was not observed, neither did the analysis of the tumor weight reveal a significant difference between tumors of HAdV-5- and HAdV-5wt-injected eggs (Fig. 6C).

\section{DISCUSSION}

The treatment of solid cancers with oncolytic viruses is an emerging area of significant medical interest. Various DNA and RNA viruses are under preclinical and/or 
A
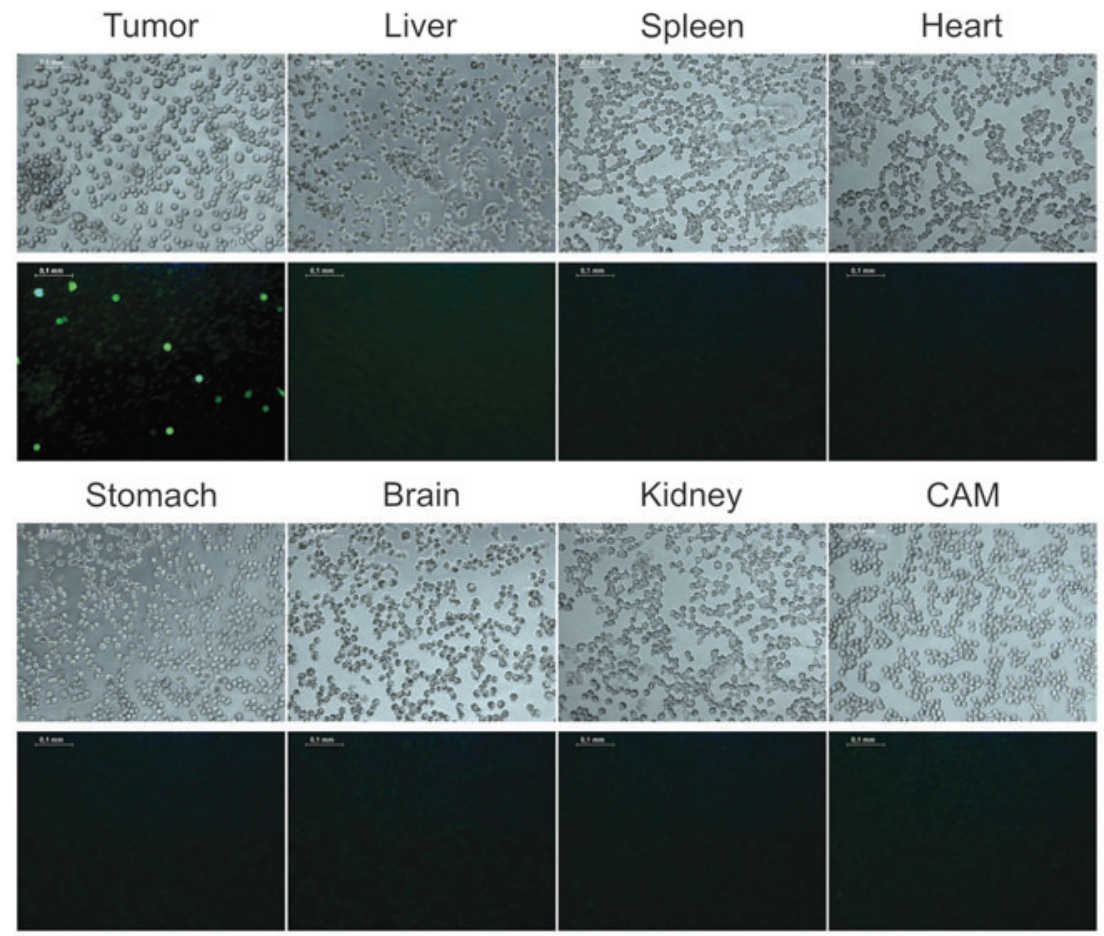

Kidney

CAM

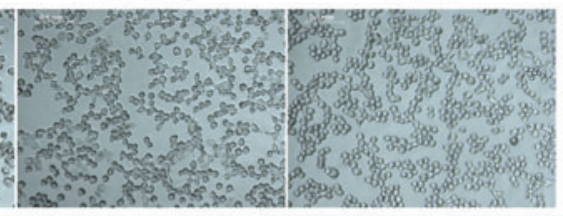

\section{B}

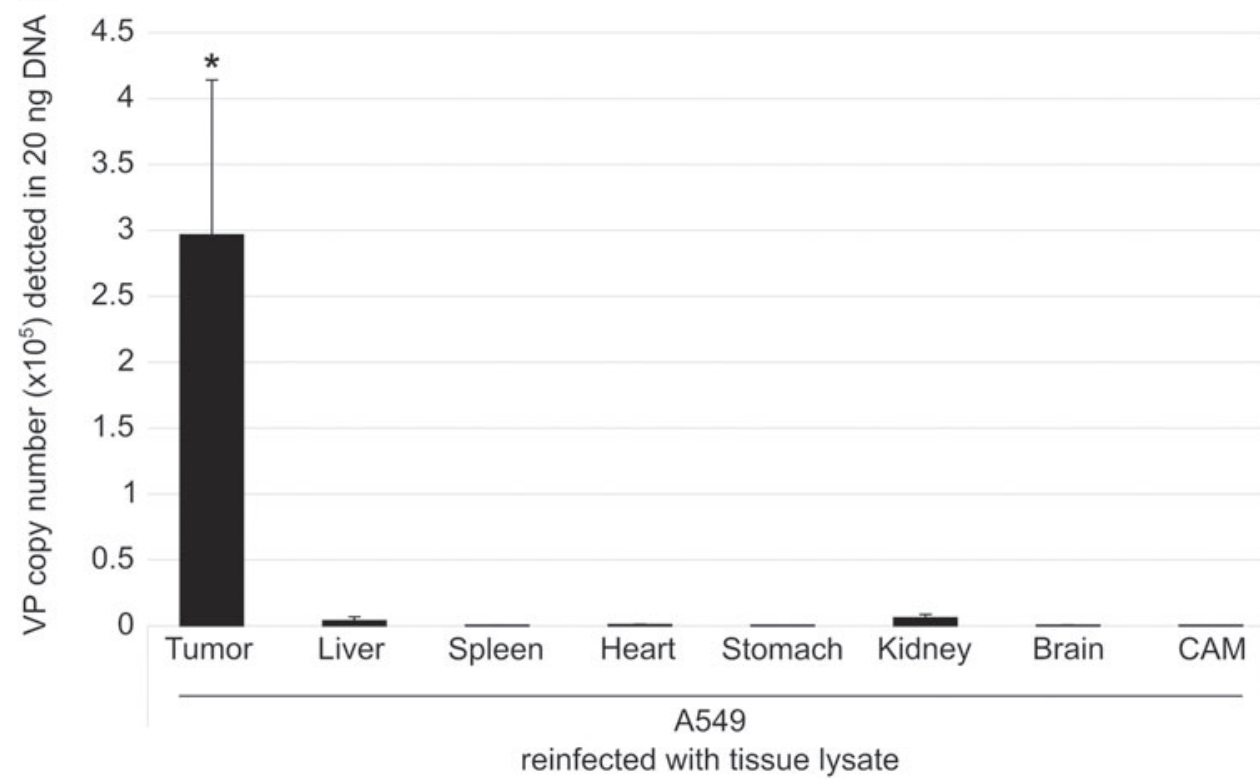

Figure 4. Chick is not permissive for HAdV-5wt replication. 5E9 eGFP-expressing, replication-competent wild-type HAdV-5wt virus particles dissolved in $50 \mu \mathrm{L}$ PBS were intravenously injected in human UM-SCC-11B tumor-bearing chicken eggs at E12. At E14, chicks were sacrificed and tumors and chick organs harvested. Tissue cells were homogenized and lysed by repeated freeze/thaw cycles. Cells lysates were used to reinfect 2E4 A549 cells, seeded the day before. A549 cells were incubated for $3 \mathrm{~h}$ at $37^{\circ} \mathrm{C}$, extensively washed, and subsequently either (A) incubated for further $20 \mathrm{~h}$ in $200 \mu \mathrm{L}$ serous medium, before the eGFP-expression was analyzed by microscopy, or (B) harvested, and the DNA extracted. The intracellular vector copy number was quantified by qPCR and normalized with human $\beta$-actin copy numbers. Results are given as mean of $n=3 \pm$ standard deviation. ${ }^{*} p<0.05$.

clinical evaluation as virotherapeutics. ${ }^{44}$ The preclinical development of oncolytic virus candidates is cumbersome and only a small proportion of newly developed viruses actually qualify to enter clinical development. The far greater part fails during different stages of preclinical testing. In vivo testing of viruses for cancer therapy al- most exclusively is performed in animals, mostly either in syngeneic or in xenograft cancer models. These studies have to be performed under strict animal welfare regulations and they are time-consuming and costly.

In contrast, the CAM tumor model is a quick and easy alternative for the use of mammalian animal cancer 

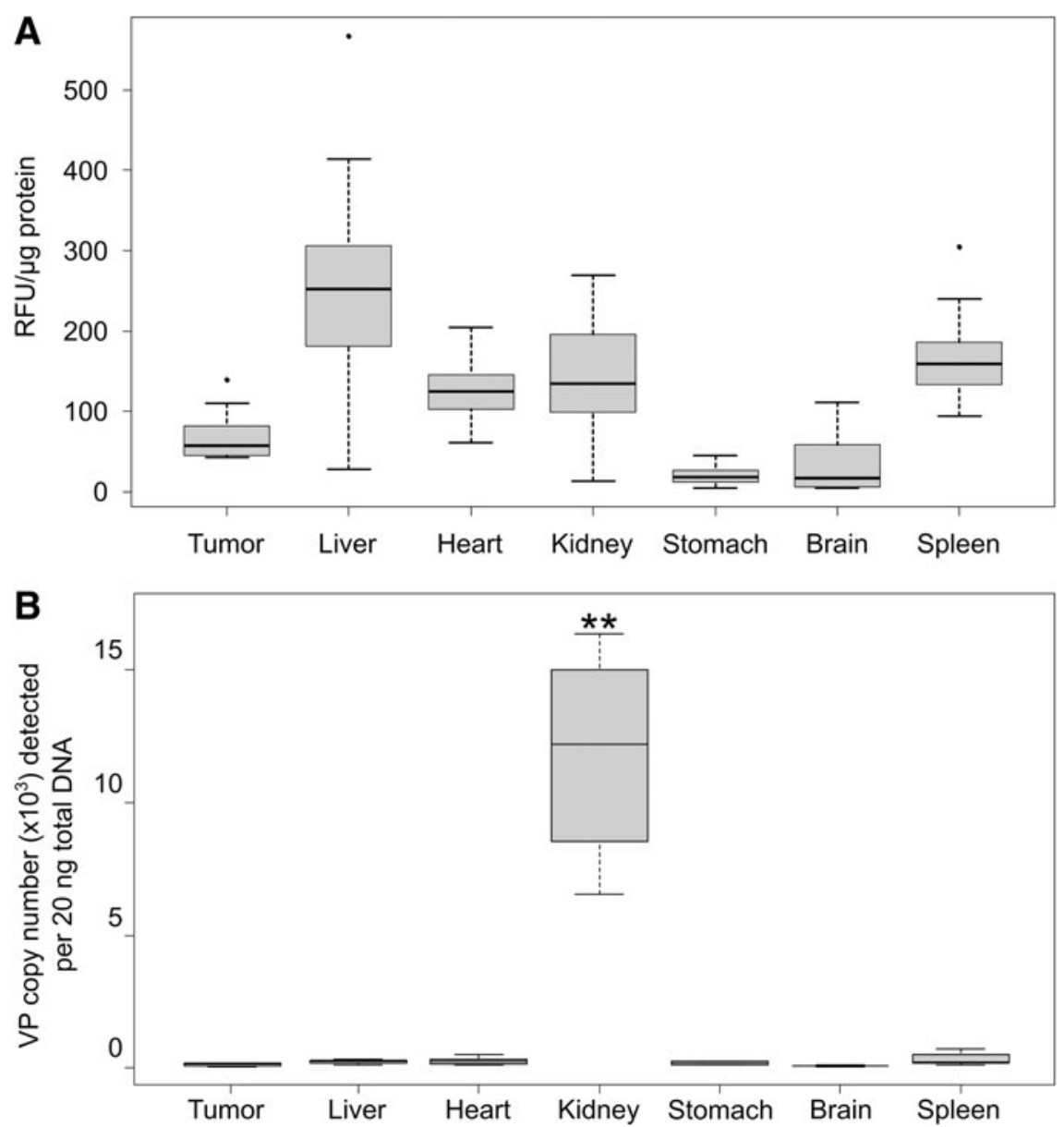

Figure 5. In ovo biodistribution of HAdV-5 particles in tumor-bearing fertilized chicken eggs. 5E9 eGFP-expressing, replication-incompetent HAdV-5 vector particles dissolved in $50 \mu \mathrm{L}$ PBS were intravenously injected in human UM-SCC-11B tumor-bearing chicken eggs at E12. At E14, chicks were sacrificed and tumors and chick organs harvested. (A) Tumors and organs were homogenized, protein concentrations determined by measurement of the optical density at $280 \mathrm{~nm}$, and the eGFP fluorescence intensity analyzed using a fluorospectrometer $(n=19)$. (B) Tumors and tissues were harvested and total DNA extracted. The vector genome copy number of $20 \mathrm{ng}$ total DNA was quantified by qPCR and normalized with human $\beta$-actin copy numbers $(n=7) .{ }^{* *} p<0.005$. RFU, response fluorescence units.

models. Considerable advantages are the fast tumor development, good vascularization, redundancy of approval by an animal ethics committee, low acquisition and maintenance costs, good tumor accessibility and monitoring, and natural absence of an immune system. In addition, the model allows the use of tumor biopsies that can be cultivated on the CAM for several days. ${ }^{45}$ Primary tumor biopsies are a very valuable tissue source since they depict the heterogenous composition of a naturally grown tumor, however, more intricately applicable in mammalian animal models. Due to the easy access to the membrane, another interesting opportunity for the CAM model is the potential use of in vitro grown 3D tumors or the application of heterogenous cell mixtures consisting not only of tumor cells but also of cells and components of the tumor microenvironment. A further important advantage of the CAM model is also the associated opportunity to reduce the number of animal experiments, according to the $3 R$ principles.
To our knowledge, the CAM model has been used in only a few publications for the analysis of virus-induced lysis or targeting of tumors grown in ovo. Most of them focused on the evaluation of virus-induced angiogenetic effects. ${ }^{5,7,8,11}$ Reasons for this neglect might be the fragmentary scientific knowledge about this model system, difficulties in its setup, and lack of standardization. Just two publications, both using adenoviruses, used the CAM model with the aim to examine the oncolytic effect of the virus and the tumor targeting efficiency. ${ }^{9,10}$ Durupt et al. injected replication-competent adenoviral particles intratumorally. Six days postinjection they observed cell necrosis at virus injection sites, but neither i.t. virus spread nor a reduction of tumor sizes. ${ }^{9}$ Kaczorowski et al. injected adenoviral particles alone or packed in mesenchymal stromal cells intravenously and subsequently analyzed the tumor targeting efficiency. Using the CAM model, they could prove the beneficial effect of mesenchymal stromal cells (MSCs) as tumor-targeting carrier 

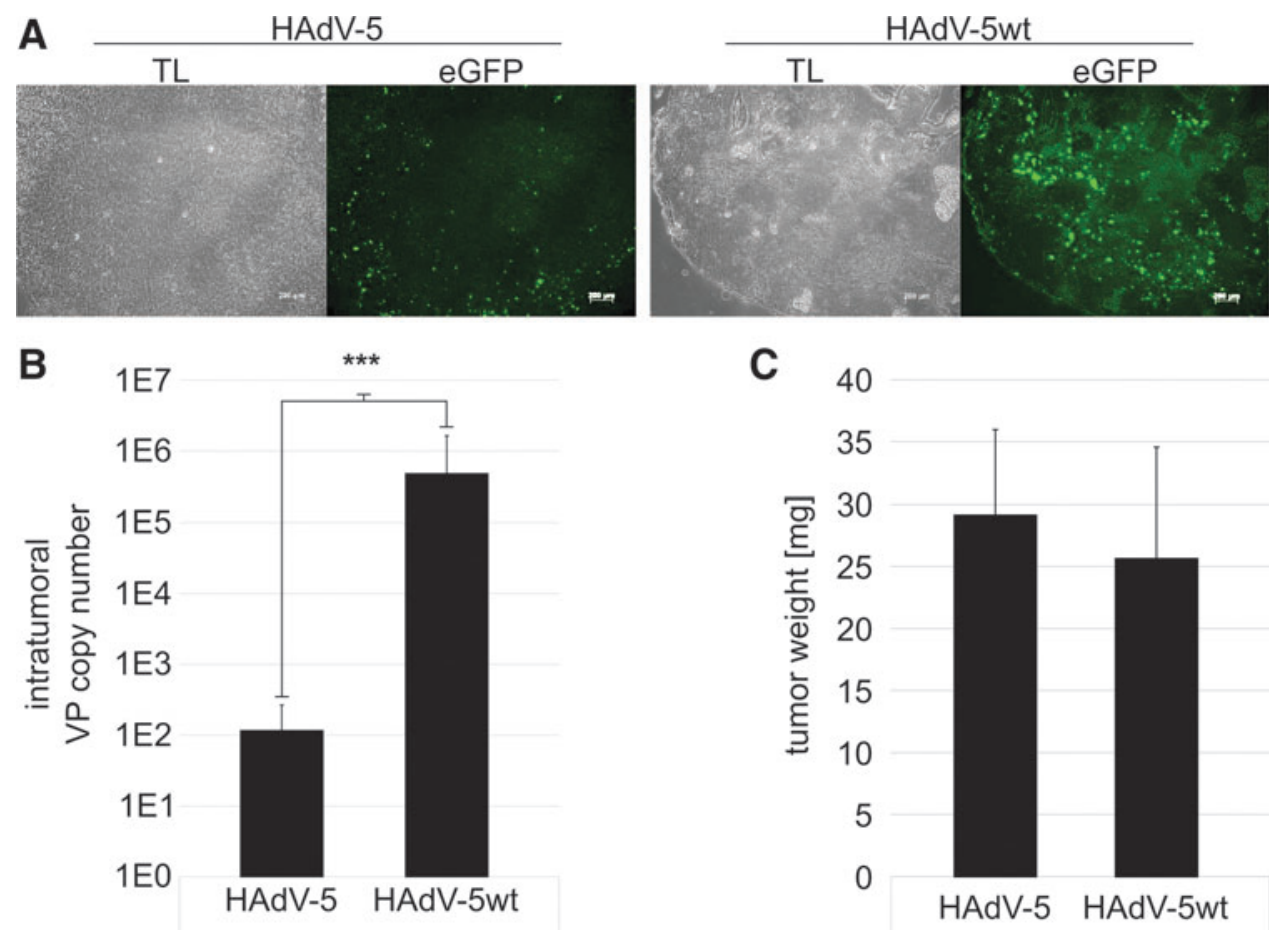

Figure 6. Intratumoral virus replication but insufficient oncolysis. 5E9 eGFP-expressing, replication-competent HAdV-5wt virus or replication-incompetent HAdV-5 vector particles dissolved in $50 \mu$ L PBS were intravenously injected in human UM-SCC-11B tumor-bearing chicken eggs at E11. At E16, chicks were sacrificed and tumors harvested. (A) Six-micron cryosections of tumors were prepared and analyzed for eGFP-expressing cells by fluorescence microscopy. Fivefold magnification, representative data of $n=3$. (B) Total DNA of tumors was extracted. The viral genome copy number of $20 \mathrm{ng}$ total DNA was quantified by qPCR and normalized to human $\beta$-actin copy numbers $(n=14-15)$. (C) Tumors were weighed after excision $(n=17-18)$. Scale bar: $200 \mu \mathrm{m},{ }^{* * *} p<0.0005$.

cells for oncolytic adenoviruses. Concurrently, they mentioned that they did not detect viral particles in chick liver, heart, or lung tissue. However, they used immunohistochemistry for the detection of viral capsids. Here we show that the chick is not permissive for adenovirus replication, and thus, it is likely that the initial delivered amount of virus that did not, in contrast to the human tumor tissue, amplify within the liver, heart, and lung tissue was below the detection limit. ${ }^{10}$ Taken together, none of the studies characterized the model itself by thorough analysis of virus-host interactions or compared this system to the widely used xenograft tumor mouse models. To fill this gap, we thoroughly examined the interactions of HAdV-5 with the chick.

During the course of experiments, we identified several important technical challenges. Strict adherence to the here given timescale, as well as to cell and virus concentrations, significantly increases the tumor take rate and the chick survival rate, respectively. Critical for the successful implementation of this model system is a thorough hemostasis after i.v. injection. We found that retaining the cannula in the vessel and fixing it to the eggshell works best (Supplementary Video S1). Moreover, for animal care reasons, we also consider it important to use a reliable method to sacrifice the chick. Especially when egg incubation times exceed, E12 sensation of pain is likely, since from day E13 onward, the neural tube is fully developed. Aleksandrowicz and Herr discussed the development of awareness in chicks and other possibilities to sacrifice the chick than the here-described overdosed propofol injections. ${ }^{46}$

Our data show that the in ovo CAM is a reliable model for the analysis of virus-host interactions and mirrors results obtained with immunocompromised xenograft mouse models. It allows both i.t. and i.v. virus administration. Just as mice, the chick is not permissive for human adenovirus replication and HAdV -5 does not bind to chick erythrocytes. The analysis of HAdV-5 interaction with noncellular chick blood components showed that chick plasma significantly enhanced in vitro cell transduction by HAdV-5. This indicates that likely avian FX binds to the adenoviral capsid and bridges cell transduction, as reported from murine and human FX. ${ }^{18,23,36,47}$ Moreover, we did not observe neutralization of FX binding-ablated $\mathrm{HAdV}-5-\Delta \mathrm{FX}$ vector particles when incubated with chick plasma. ${ }^{18}$ This indicated the absence of natural antibodies at least until E14, as it is the case in the widely used immunodeficient NSG mouse model. This hypothesis is supported by the knowledge that the chicks' immune system fully develops not until the first weeks after hatching. ${ }^{48}$ Interestingly, chick plasma similar to NSG plasma slightly enhanced cell transduction 
by HAdV-5- $\Delta \mathrm{FX}$ vectors. Given the fact that the used particles do not bind FX anymore, this enhancement most potentially can be attributed to the binding of other blood (coagulation) factors to the viral capsid. It has been shown that murine and human FVII and FIX also bind to the adenoviral fiber protein and slightly support cell transduction. $^{35,49}$ Thus, our data may suggest that also in chick plasma various blood components, including coagulation factors, may bind to the adenoviral capsid. Regarding in ovo vector biodistribution profiles, the CAM model mirrors results obtained in mice ${ }^{31,32}$ : upon i.v. injection most of the vector particles transduced hepatic cells followed by splenic cells. Intermediate transduction levels were measured in tumors, kidneys, and hearts, while hardly any or no transduction was observed in the brain and stomach. These data suggest that the CAM model is a suitable alternative to the mouse model to investigate tumor targeting approaches with oncolytic adenoviruses and most likely other oncolytic viruses. Approaches based on viruses with chemically attached or genetically introduced tumor-targeting ligands or modified by other targeting strategies can significantly benefit from this quick and easy method to evaluate tumor infection levels upon i.t. or i.v. injections. However, it has to be mentioned that standard deviations within experiments are comparatively high with this model system, and thus, relatively large group sizes are required.

Similarly like Durupt et al., we did not observe any immediate oncolytic effect of i.v.-administered replication-competent HAdV-5wt particles. ${ }^{9}$ Even after prolonged incubation of 5 days, there was no measurable delay in tumor growth or tumor shrinkage compared with control eggs. However, histological analysis of tumor sections and detection of viral DNA copy numbers in the tumors clearly confirmed replication of HAdV-5wt virus particles. We assume that the observation period of only a few days, until the CAM assay has to be terminated due to animal welfare reasons, was too short to allow a clinical observation of virus-induced oncolytic effects. Nonetheless, replication efficiency was quantifiable, and thus, comparison of differently modified virus particles is feasible with this model. Moreover, it is noteworthy that human adenoviruses have a comparably long life cycle of about 48-72 h, while the life cycle of, for instance, reoviruses (18-24h), herpes simplex viruses (18-20 h), or retroviruses $\left(8-12 \mathrm{~h}\right.$ ) is significantly shorter. ${ }^{50-52}$ Thus, it is possible that the CAM models will be very likely suitable to phenotypically observe oncolytic effects induced by viruses with a shorter replication cycle. Furthermore, tumor-destructive effects of virus-delivered anticancer drugs can likely be measured with this model, as they act faster than the virus replicates. Aside from that, the use of turkey eggs could be an interesting alternative to chicken eggs. The turkey hatches after 28 days of breeding, while the chick already hatches after 21 days. Thus, turkey eggs may offer the opportunity to increase incubation times of virus-injected tumors.

In summary, the CAM tumor model may be a feasible alternative for in vivo studies based on murine xenograft tumor models. Here we show that this model allows the analysis of relevant vector-host interactions of adenoviral particles. Moreover and not limited to only oncolytic adenoviruses but relating to oncolytic viruses in general, we illustrate that the CAM model is suitable for the evaluation of biodistribution profiles and tumor targeting efficiencies of modified viruses, both upon i.t. and i.v. administration. The model does not facilitate the investigation of adenovirus-induced tumor lysis due to a too short observation period. However, it is possible that tumor lysis could be observed with oncolytic viruses that have shorter life cycles.

\section{ACKNOWLEDGMENTS}

The authors acknowledge Dr. Ninel Azoitei and Kristina Diepold for the technical advice on the basic implementation of the CAM model.

\section{AUTHOR DISCLOSURE}

No competing financial interests exist.

\section{FUNDING INFORMATION}

No funding was received for this article.

\section{SUPPLEMENTARY MATERIAL}

Supplementary Video S1

Supplementary Figure S1 


\section{REFERENCES}

1. Bluming AZ, Ziegler JL. Regression of Burkitt's lymphoma in association with measles infection. Regres Burkitts Lymphoma Assoc Measles Infect 1971;105-106.

2. Russell L, Peng K-W. The emerging role of oncolytic virus therapy against cancer. Chin Clin Oncol 2018;7:16.

3. Murphy JB. Transplantability of tissues to the embryo of foreign species: its bearing on questions of tissue specificity and tumor immunity. J Exp Med 1913;17:482-493.

4. Murphy JB, Rous P. The behavior of chicken sarcoma implanted in the developing embryo. J Exp Med 1912;15:119-132.

5. Mullen JT, Donahue JM, Chandrasekhar S, et al. Oncolysis by viral replication and inhibition of angiogenesis by a replication-conditional herpes simplex virus that expresses mouse endostatin. Cancer 2004;101:869-877.

6. Fan JK, Xiao T, Gu JF, et al. Increased suppression of oncolytic adenovirus carrying mutant $\mathrm{k} 5$ on colorectal tumor. Biochem Biophys Res Commun 2008;374:198-203.

7. Ong HT, Trejo TR, Pham LD, et al. Intravascularly administered RGD-displaying measles viruses bind to and infect neovessel endothelial cells in vivo. Mol Ther J Am Soc Gene Ther 2009;17: 1012-1021.

8. Xiao T, Fan JK, Huang HL, et al. VEGI-armed oncolytic adenovirus inhibits tumor neovascularization and directly induces mitochondria-mediated cancer cell apoptosis. Cell Res 2010;20:367-378.

9. Durupt F, Koppers-Lalic D, Balme B, et al. The chicken chorioallantoic membrane tumor assay as model for qualitative testing of oncolytic adenoviruses. Cancer Gene Ther 2012;19:58-68.

10. Kaczorowski A, Hammer K, Liu L, et al. Delivery of improved oncolytic adenoviruses by mesenchymal stromal cells for elimination of tumorigenic pancreatic cancer cells. Oncotarget 2016;7:90469059

11. Schughart K, Accart N. Use of adenovirus vectors for functional gene analysis in the chicken chorioallantoic membrane. BioTechniques 2003;34: 178-183.

12. Ribatti D. The chick embryo chorioallantoic membrane (CAM) assay. Reprod Toxicol 2017;70: 97-101.

13. U.S. National Library of Medicine-Clinical Trials. https://clinicaltrials.gov/ct2 (last accessed February 28,2020 )

14. Carlisle RC, Di Y, Cerny AM, et al. Human erythrocytes bind and inactivate type 5 adenovirus by presenting Coxsackie virus-adenovirus receptor and complement receptor 1. Blood 2009;113: 1909-1918.

15. Cichon G, Boeckh-Herwig S, Kuemin D, et al. Titer determination of Ad5 in blood: a cautionary note. Gene Ther 2003;10:1012-1017.
16. Sumida SM, Truitt DM, Lemckert AAC, et al. Neutralizing antibodies to adenovirus serotype 5 vaccine vectors are directed primarily against the adenovirus hexon protein. J Immunol 2005;174: 7179-7185.

17. Xu Z, Tian J, Smith JS, et al. Clearance of adenovirus by Kupffer cells is mediated by scavenger receptors, natural antibodies, and complement. J Virol 2008;82:11705-11713.

18. Xu Z, Qiu Q, Tian J, et al. Coagulation factor $X$ shields adenovirus type 5 from attack by natural antibodies and complement. Nat Med 2013;19: 452-457.

19. Khare R, May SM, Vetrini F, et al. Generation of a Kupffer cell-evading adenovirus for systemic and liver-directed gene transfer. Mol Ther J Am Soc Gene Ther 2011:19:1254-1262.

20. Schiedner G, Hertel $S$, Johnston $M$, et al. Selective depletion or blockade of Kupffer cells leads to enhanced and prolonged hepatic transgene expression using high-capacity adenoviral vectors. Mol Ther J Am Soc Gene Ther 2003;7: 35-43.

21. Li Q, Kay MA, Finegold M, et al. Assessment of recombinant adenoviral vectors for hepatic gene therapy. Hum Gene Ther 1993;4:403-409.

22. Kirby I, Davison E, Beavil AJ, et al. Identification of contact residues and definition of the CARbinding site of adenovirus type 5 fiber protein. J Virol 2000;74:2804-2813.

23. Krutzke L, Prill JM, Engler T, et al. Substitution of blood coagulation factor $\mathrm{X}$-binding to $\mathrm{Ad} 5$ by position-specific PEGylation: preventing vector clearance and preserving infectivity. J Controlled Release 2016;235:379-392.

24. Schiedner G, Hertel S, Kochanek S. Efficient transformation of primary human amniocytes by E1 functions of Ad5: generation of new cell lines for adenoviral vector production. Hum Gene Ther 2000;11:2105-2116

25. Mittereder N, March KL, Trapnell BC. Evaluation of the concentration and bioactivity of adenovirus vectors for gene therapy. J Virol 1996;70:74987509 .

26. Lyons M, Onion D, Green NK, et al. Adenovirus type 5 interactions with human blood cells may compromise systemic delivery. Mol Ther J Am Soc Gene Ther 2006;14:118-128.

27. Schindelin J, Arganda-Carreras I, Frise E, et al. Fiji: an open-source platform for biologicalimage analysis. Nat Methods 2012;9:676682.

28. Schneider CA, Rasband WS, Eliceiri KW. NIH Image to Image J: 25 years of image analysis. Nat Methods 2012:9:671-675.

29. Nguyen TV, Barry ME, Turner MA, et al. Comparison of liver detargeting strategies for systemic therapy with oncolytic adenovirus serotype 5 . Biomedicines 2017:5:46.
30. R Core Team. R: A language and environment for statistical computing. Vienna, Austria: R Foundation for Statistical Computing. www.R-project.org 2016 (last accessed February 28, 2020).

31. Alba R, Bradshaw AC, Coughlan L, et al. Biodistribution and retargeting of FX-binding ablated adenovirus serotype 5 vectors. Blood 2010;116 2656-2664

32. Alemany R, Curiel DT. CAR-binding ablation does not change biodistribution and toxicity of adenoviral vectors. Gene Ther 2001:8:1347-1353.

33. Duffy MR, Doszpoly A, Turner G, et al. The relevance of coagulation factor $X$ protection of adenoviruses in human sera. Gene Ther 2016;23: $592-596$.

34. Ma J, Duffy MR, Deng L, et al. Manipulating adenovirus hexon hypervariable loops dictates immune neutralisation and coagulation factor $\mathrm{X}$-dependent cell interaction in vitro and in vivo. PLoS Pathog 2015;11:e1004673.

35. Parker AL, Waddington SN, Nicol CG, et al. Multiple vitamin K-dependent coagulation zymogens promote adenovirus-mediated gene delivery to hepatocytes. Blood 2006;108:2554-2561.

36. Waddington SN, McVey JH, Bhella D, et al. Adenovirus serotype 5 hexon mediates liver gene transfer. Cell 2008;132:397-409.

37. Mink JG, Radl J, van den Berg P, et al. Serum immunoglobulins in nude mice and their heterozygous littermates during ageing. Immunology 1980:40:539-545

38. Diaconu I, Cerullo V, Escutenaire S, et al. Human adenovirus replication in immunocompetent Syrian hamsters can be attenuated with chlorpromazine or cidofovir. J Gene Med 2010;12:435-445.

39. Gordon YJ, Romanowski E, Araullo-Cruz T. An ocular model of adenovirus type 5 infection in the NZ rabbit. Invest Ophthalmol Vis Sci 1992;33:574580.

40. Prevec L, Schneider M, Rosenthal KL, et al. Use of human adenovirus-based vectors for antigen expression in animals. J Gen Virol 1989;70 (Pt 2): 429-434.

41. Steel JC, Morrison BJ, Mannan P, et al. Immunocompetent syngeneic cotton rat tumor models for the assessment of replicationcompetent oncolytic adenovirus. Virology 2007; 369:131-142.

42. Ginsberg HS, Moldawer LL, Sehgal PB, et al. A mouse model for investigating the molecular pathogenesis of adenovirus pneumonia. Proc Nat Acad Sci U S A 1991;88:1651-1655.

43. Zaefarian F, Abdollahi M, Cowieson $A$, et al. Avian liver: the forgotten organ. Animals 2019; 9:63.

44. Pol JG, Lévesque S, Workenhe ST, et al. Trial Watch: oncolytic viro-immunotherapy of hematologic and solid tumors. Oncolmmunology 2018;7: e1503032. 
45. Dohle DS, Pasa SD, Gustmann S, et al. Chick ex ovo culture and ex ovo CAM assay: how it really works. J Vis Exp 2009;30:1620.

46. Aleksandrowicz E, Herr I. Ethical euthanasia and short-term anesthesia of the chick embryo. ALTEX 2015;32:143-147.

47. Irons EE, Flatt JW, Doronin K, et al. Coagulation factor binding orientation and dimerization may influence infectivity of adenovirus-coagulation factor complexes. J Virol 2013:87:9610-9619.

48. Janković BD, Isaković K, Marković BM, et al. Immunological capacity of the chicken embryo. II.
Humoral immune responses in embryos and young chickens bursectomized and sham-bursectomized at 52-64 h of incubation. Immunology 1977;32: 689-699.

49. Shayakhmetov DM, Gaggar A, Ni S, et al. Adenovirus binding to blood factors results in liver cell infection and hepatotoxicity. J Virol 2005;79: 7478-7491.

50. Ghani K, Cottin S, Kamen A, et al. Generation of a high-titer packaging cell line for the production of retroviral vectors in suspension and serum-free media. Gene Ther 2007;14:1705-1711.
51. Kukhanova MK, Korovina AN, Kochetkov SN. Human herpes simplex virus: life cycle and development of inhibitors. Biochem Biokhimiia 2014; 79:1635-1652.

52. Mohamed A, Johnston RN, Shmulevitz M. Potential for improving potency and specificity of reovirus oncolysis with next-generation reovirus variants. Viruses 2015;7:6251-6278.

Received for publication February 26, 2020; accepted after revision June 8, 2020

Published online: June 18, 2020. 